\title{
NOSE-ANGLE BRIDGE PIERS AS ALTERNATIVE COUNTERMEASURES FOR LOCAL SCOUR REDUCTION
}

\author{
Ibtesam Abudallah HABIB ${ }^{1}$, Wan Hanna Melini Wan MOHTAR ${ }^{1 *}$, Atef ELSAIAD ${ }^{2}$, \\ Ahmed EL-SHAFIE ${ }^{3}$ \\ ${ }^{1}$ Dept of Civil and Structural Engineering, Universiti Kebangsaan Malaysia, Bandar Baru Bangi, Selangor, Malaysia \\ ${ }^{2}$ Dept of Water and Water Structures Engineering, Faculty of Engineering, Zagazig University, Egypt \\ ${ }^{3}$ Dept of Civil Engineering, Universiti Malaya, Jalan Universiti, Kuala Lumpur, Wilayah Persekutuan Kuala \\ Lumpur, Malaysia
}

Received 08 May 2017; accepted 21 December 2017

\begin{abstract}
This study investigates the performance nose-angle piers as countermeasures for local scour reduction around piers. Four nose angles were studied, i.e., $90^{\circ}, 70^{\circ}, 60^{\circ}$ and $45^{\circ}$ and tested in a laboratory. The sediment size was fixed at $0.39 \mathrm{~mm}$ whereas the flow angle of attack (or skew angle) was varied at four angles, i.e., skew angles, i.e., $0^{\circ}, 10^{\circ}, 20^{\circ}$ and $30^{\circ}$. Scour reduction was clear when decreasing nose angles and reached maximum when the nose angle is $45^{\circ}$. Increasing the flow velocity and skew angle was subsequently increasing the scour profile, both in vertical and transversal directions. However, the efficiency of nose angle piers was only high at low Froude number less than 0.40 where higher Froude number gives minimal changes in the maximum scour depth reduction. At a higher skew angle, although showed promising maximum scour depth reduction, the increasing pier projected width resulted in the increase of transversal lengths.
\end{abstract}

Keywords: local scour countermeasure, nose-angle pier, skew angle.

\section{Introduction}

Recent scour-related bridge catastrophes throughout the world have received much attention due to its massive impact, particularly on the economy (Akib, Mamat, Basser, \& Jahangirzadeh, 2014). Scour is a worldwide phenomenon and of great concern especially to civil engineers. Bridges on a river or a stream play a vital role in economic, social and cultural improvement in any country. More than 1000 bridges have collapsed over the past 30 years in the United States of America (USA), with $60 \%$ of the failures occurring due to scour. This severe problem also occurred in many East Asian countries, such as Taiwan, Japan, Korea, because these areas are subjected to several typhoon and flood events each year during the summer and fall seasons. Scour failure tends to occur suddenly and without warning or sign of distress to the structure (Lin, Chen, Chang, Chen, \& Lai, 2004). According to the National Transportation Safety Board (1990), the 1989 catastrophic collapse of the several bridges over the Hatchie River in Tennessee (USA) resulted in the death of eight people. In an intensive study of bridge failures in the United States, (Ross, Sicking, Zimmer, \& Michie, 1993) reported that the Federal Highways Administration in 1978 claimed damages to bridges and highways from major regional floods in 1964 and 1972 were estimated about $\$ 100$ million per event.

The local scour caused by the formation of vortices, i.e., the horseshoe vortex at the boundary layer and the impinging down-flow of water at the upstream surface of the pier due to the flow acceleration. This vortex action removes bed material from the base, particularly at the region where the piers are in contact with the bed material. Also, the water surface rises upstream of the pier, forming an emerging circular profile known as bow wave (Grimaldi, Gaudio, Cardoso, \& Calomino, 2006). A scour hole formed when the transport rate of sediments removed from the base region is larger than the transport rate of sediment added into the base region. As the depth of scouring continues to increase, the strength of the horseshoe vortex is reduced, and the transport rate of sediment away from the base region is eventually decreased. For clear-water scour (that is a flow without bed load), the scouring ceases

*Corresponding author. E-mail: hanna@ukm.edu.my 
when the shear stress of the horseshoe vortex equals to the critical shear stress of bed particles, thereby reducing the transport rate from the base region (Lagasse, Clopper, \& Zevenbergen, 2007; Richardson \& Davis, 2001).

For safe and economical design, scour around the bridge piers are required to be controlled. The performance of any scour protection/controlling device around bridge piers depends on how the device counters the scouring process. Efforts have been made to reduce the depth of scour by placing the riprap around the pier, providing an array of piles in front of the pier (Ferraro, Tafarojnoruz, Gaudio, \& Cardoso, 2013), a delta-wing-like fin in front of the pier (Gupta \& Gangadharaiah, 1992), a collar around the pier (Chiew, 1992), submerged vanes (Odgaard \& Wang, 1987), a delta-wing-like fin in front of the pier (M. Beg \& S. Beg, 2013), a slot through the pier (Chiew, 1992; Kumar, Raju, \& Vittal, 1999) and partial pier-groups and tetrahedron frames placed around the pier. The shape of the pier appreciably affects the scour depth because it reflects the strength of the horseshoe vortex at the base of the pier.

Protecting bridges against local scouring is one of the necessary elements in designing structures on rivers through implementing various scour protection measures. Two primary countermeasure techniques employed for preventing or minimizing local scour at bridge piers are classified into two categories:

(i) bed-armouring countermeasures, and

(ii) flow-altering mechanism.

In the former case, the aim is to combat the erosive action of the scour inducing mechanisms using hard engineering materials or physical barriers such as rock riprap. On the other hand, flow-altering mechanism reduces the turbulence intensity and minimizes the formation of horseshoe vortices at the bed.

The most common used countermeasure is riprap. However, riprap causes secondary scour, and the stability is compromised with passing the time and flood events. Furthermore, the efficiency is reduced when dunes are a presence and with irregular bed topography (Yoon \& Kim, 2001). Popular choices of flow altering mechanism such as collar provides an obstacle for the down-flow and reduces the strength of the horseshoe vortex. The scour reduction efficiency of collars has already been established in earlier studies (Chiew, 1992; Zarrati, Nazariah, \& Mashahir, 2006). In general, the use of collar with bridge pier appears to be effective in reducing the scour depth at the pier site. However, when the bed material at the pier site that is protected by the collar is removed and transported by the flowing water, the pier beneath the collar is exposed, and under such a condition, it loses its effectiveness (Chiew, 1992).

Recent studies have employed slots as an approach to reducing the power of horseshoe vortex, by creating a conduit for passing the flow through the pier of the bridge. The intensity of the downward flow is reduced, and the formation of horseshoe vortex is weakening, subsequently reducing the local scour depth. The location of slots plays an important role, where near the water surface reduces the effective depth of flow as well as the pressure gradient. However, the best position of slots was found to be at near bed.

In general, all methods have given good results in the reduction of local scour around bridge piers; however, they were unable to give consistent protection due to secondary scour and stability issue. Pier shape has a significant factor and obtaining the optimum pier shape reduced the needs of additional countermeasures of bed armouring. As such, this study attempts to investigate the effect of bridge pier shape of non-traditional nose angled. The proposed shape increases the attack surface area, which hypothetically reduces the swirling vertical, down-flow and minimizes the formation of horseshoe vortex. The angle of sloped nose pier is varied, and the behaviour of each pier is investigated under varying flow characteristics including Froude number and angle of attack.

\section{Materials and methods}

Experiments were carried out in the fluid laboratory at the Faculty of Engineering, Almergeb University. The tests were conducted through a glass fiber-made open flume, with dimensions of $0.60 \times 0.20 \times 5.70 \mathrm{~m}^{3}$. A schematic diagram of the experimental setup is shown in Figure 1. The flume was connected with tanks which supply the water through a rectangular weir, placed at the entrance of the flume and is used to measure the flow rate.

The flume is divided into three parts, i.e. the inlet part, the working section and the outlet part. The inlet tank was filled with coarse gravel to reduce the turbulence of the incoming flow, and a screen is placed to ensure a uniform flow. An irregular riprap layer of $0.50 \mathrm{~m}$ length was placed before the working section at the upstream side to avoid any turbulence at the pier site. Sand with the mean diameter $d_{50}$ equal to $0.39 \mathrm{~mm}$ and the geometric standard deviation of particle size distribution $\sigma_{g}=\sqrt{\frac{d_{84}}{d_{16}}}=1.29 \mathrm{~mm}$ ( $\sigma_{\mathrm{g}}$ less than 1.30 uniform sediment) was used. The bed slope remained horizontal for all experiments. For all experiments, $\frac{b}{d_{50}}$ more than 50 to avoid any influence of sediment coarseness.

The flow discharge was measured using a rectangular weir was located at the outlet of working section. To avoid any turbulence at the pier site, a riprap layer of $0.50 \mathrm{~m}$ length and slab of sponge, of length $25 \mathrm{~cm}$ and thickness of $15 \mathrm{~cm}$, was put at the entrance of the working section at the upstream side after the weir. The dis-

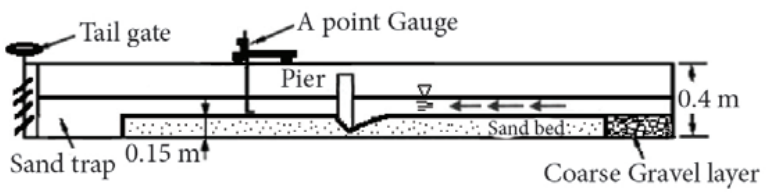

Figure 1. Schematic diagram of the experimental setup in a flume 
Table 1. The dimensions of the tested models

\begin{tabular}{|c|c|c|c|c|}
\hline Model No. & $L, \mathrm{~cm}$ & $b, \mathrm{~cm}$ & $H, \mathrm{~cm}$ & Nose angle $\theta,^{\circ}$ \\
\hline 1 & 20.00 & 4 & 20 & $90^{\circ}$ \\
\hline 2 & 20.00 & 4 & 20 & $70^{\circ}$ \\
\hline 3 & 20.00 & 4 & 20 & $60^{\circ}$ \\
\hline 4 & 20.00 & 4 & 20 & $45^{\circ}$ \\
\hline
\end{tabular}

charge was calibrated using a volumetric method using water height above the crest of the weir $H_{w}$ and resulted in $Q=1.288 H_{w}^{1.3453}$, where the unit of discharge $Q$ is $1 / \mathrm{sec}$. The flow rate ranged between $01 / \mathrm{sec}$ to $41 / \mathrm{sec}$ and the upstream water depths $\left(h_{u}\right)$ were varied between $11 \mathrm{~cm}$ to $12 \mathrm{~cm}$. Froude number $\left(F_{r}=\frac{V}{\sqrt{h_{u} g}}\right.$, where $V$ is the mean flow velocity and $g$ denotes gravity acceleration) during these experiments were varied from 0.11 to 0.79 . The experiments were conducted in clear water condition to readily observe the maximum scouring depths.

Four piers of rectangular shape and semi-circular ends were tested, where the pier dimensions for all models are shown in Table 1. The width of models was less than $12 \%$ of flume width to avoid contraction effects, and $\frac{b}{l}$ ( $b$ is the width of pier and $L$ is the length of the pier) were less than or equal to $\frac{1}{3}$ based on Chiew and Melville (1987) recommendations.

The pier model was first installed in the middle of the working area to start the experiment. Before each experiment, the bed surface was levelled using a wooden leveller to make sure a uniform horizontal bed is formed. The flume is gradually filled with water, and particular attention was paid to ensure that the incoming flow has minimal disturbance on the prepared bed. The centrifugal pump is switched on having reached the desired flow depth. For each run, the experiments were continued until the scour hole has reached its equilibrium state.

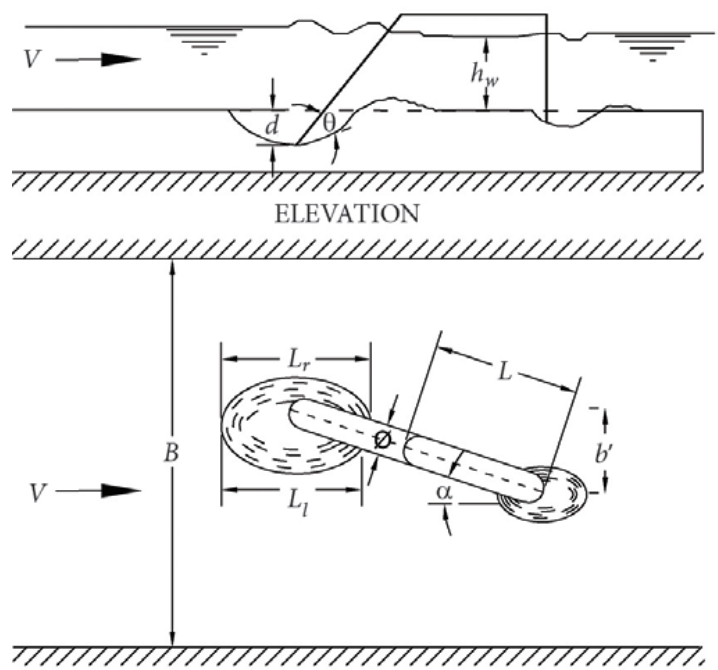

After the flume was carefully drained and left to dry, the final scour depths were measured using a point gauge with an accuracy of 0.01 . The measurement procedure was conducted by placing the gauge on adjustable stainless steel rails, located at the top flanges of the tank and the scale is able be positioned at any point within the working area. These extend over the full length of the working section. The measurements included the width of scour hole and the transversal lengths, i.e., length of scour hole at upstream of left and right sides of the pier. To give a better representation of where the measurement was taken, Figure 2 illustrates the location each parameter assessed in this experiment.

Throughout the experiments, clear water conditions were applied. Experiments were first carried out to study the effect of time on the local scour, to reach the equilibrium time. Eighty-two runs were conducted. The definition of time to scour equilibrium adopted for a given test plays a significant role in the results of a scouring experiment. To achieve equilibrium conditions, this equilibrium time and the experiments must be prolonged. The temporal measurements of scour depth were taken atequal to $40 \mathrm{~min}, 80 \mathrm{~min}, 120 \mathrm{~min}, 180 \mathrm{~min}, 240 \mathrm{~min}$ and $360 \mathrm{~min}$. The equilibrium time was taken when the depth of scour holes showed no changes more than $1 \mathrm{~mm}$.

Each pier model was tested for four different skew angles ( evaluated at $0^{\circ}, 10^{\circ}, 20^{\circ}$ and $30^{\circ}$ to investigate the effects of flow attack on scouring. In the second part and the third part of the experiments, 200 runs were achieved to test each model without attack angle and with skew angles $a$ equal to $10^{\circ}, 20^{\circ}$, and $30^{\circ}$. Based on the experiments, the equilibrium time for this set of experiments was attained at $120 \mathrm{~min}$.

In this study, it was assumed that the measured maximum scour depth $d s$ for the nose-angle bridge pier is expressed by Eq. (1):

$$
\begin{aligned}
d_{s}= & f\left(B, L, \theta, \alpha, b, b^{\prime}, l_{l}, l_{r}, W_{s}, h_{u}, h_{d}, Q, V,\right. \\
& \left.T, g, \mu, \rho_{w}, d_{50}\right),
\end{aligned}
$$

where $d_{s}$ - scour depth in upstream, $\mathrm{cm} ; l_{l}$ - length of scour hole in upstream for left side, $\mathrm{cm} ; l_{r}$ - length of scour hole

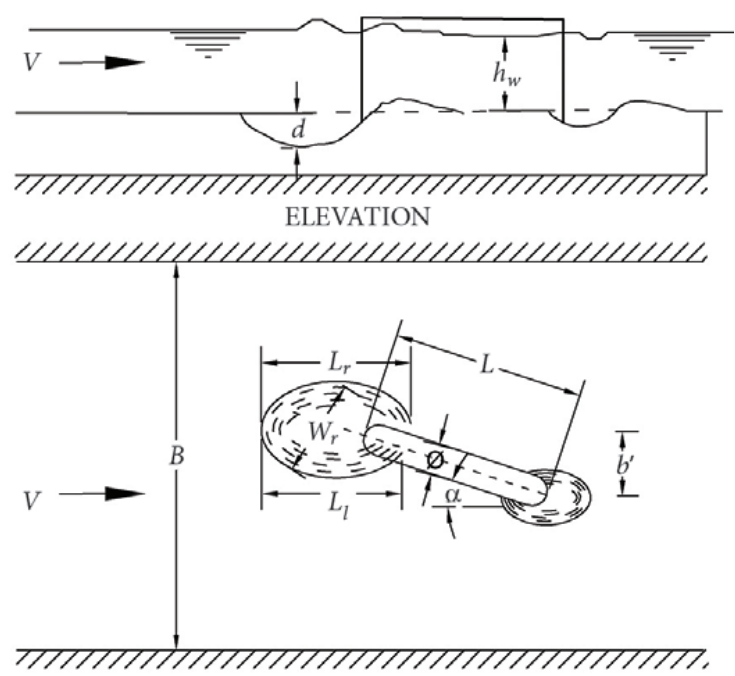

Figure 2. Schematic diagram of parameter representation measured in each experiment, initially presented by Habib (2007) 
in upstream for right side pier, $\mathrm{cm} ; W_{s}$ - width of scour hole in upstream, $\mathrm{cm} ; b$ - single pier width, $\mathrm{cm} ; L$ - pier length parallel to approach flow, $\mathrm{cm} ; B$ - width of main channel, $\mathrm{cm} ; b^{\prime}$ - the forward projected width of a rectangular pier, $\mathrm{cm} ; d_{50}$ - median sediment grain diameter, $\mathrm{cm} ; V$ - the mean flow velocity, $\mathrm{cm} / \mathrm{sec} ; Q$ - the discharge, $\mathrm{cm}^{3} / \mathrm{sec} ; h_{u}$ the upstream water depth, $\mathrm{cm} ; h_{d}$ - the downstream water depth, $\mathrm{cm} ; \mu$ - dynamic viscosity, $\mathrm{kg} / \mathrm{sec} . \mathrm{m} ; \rho w$ - water density, $\mathrm{kg} / \mathrm{m}^{3} ; \theta$ - the vertical angle of inclination of the upstream face pier, $\alpha$ - skew angles of the pier; $T$ - time, sec; $g$ - gravity acceleration, $\mathrm{m} / \mathrm{sec}^{2}$.

Consequently, based on the conditions mentioned above, $\left(d_{s}\right)$ only was considered as a function of the following parameters in Eq. (2):

$$
d_{s}=f\left(B, L, \theta, \alpha, b, b^{\prime}, h_{w}, Q, V, T, g, \mu, \rho_{w}\right) .
$$

Applying the Buckingham theory and the dimensional analysis to Eq. (2), the relative scour depth is obtained as Eq. (3):

$$
\frac{d_{s}}{b}=f^{\prime}\left(\frac{W_{s}}{b}, \frac{l_{l}}{b}, \frac{l_{r}}{b}, \frac{b^{\prime}}{b}, \frac{\alpha}{\alpha_{30}}, F_{n}, R_{b^{\prime}}, \theta, \alpha, T\right),
$$

where $R_{b^{\prime}}=\frac{V b^{\prime}}{v}$ denotes the forward projected width Reynolds number.

Statistical analysis using multi-linear regression method was used to find a general equation for estimating the relative scour depth $\frac{d_{s}}{b}$, the relative length of scour hole in the right side at upstream the pier $\frac{l_{r}}{b}$, the relative length of scour hole in the left side at upstream the pier $\frac{l_{l}}{b}$, and the relative scour width $\frac{W_{s}}{b}$.

\section{Experimental results}

\subsection{The time effect on the local scour}

Recall that eighty-two runs were carried out to study the temporal variation of local scours around the noseangle piers, for 10 hours. A representative of the data was displayed in Figure 3, which represents the relationship among relative maximum scour depth $\frac{d_{s}}{b}$ on time $\frac{T}{T_{0}}$. The time is made dimensionless with $T_{0}$, taken as the time when the equilibrium depth is achieved. Data shows that the scour depth reaches to an asymptotic value at $\frac{T}{T_{0}}$ around 0.40 , which indicate that $90 \%$ of the scour depth occurs at $40 \%$ of the final scour depth (90\% of the maximum scour depth reached at 4 hours). The rate of increase in scour depth for $\frac{T}{T_{0}}$ more than 0.40 is small. Data shows that the maximum scour depth reached up to $70 \%$ of the pier width at about $0.5 T 0$. However, to ascertain that the maximum scour depth is obtained throughout the experiment, the running time was extended to 6 hours.

\section{Analysis of the results}

The data obtained from the laboratory was divided into three analyses. Initially, the nose angle effect on the depth of scour was focused, and then the skew angle effect on the depth of scour was discussed. A Multiple Linear Regression (M.L.R) method was then applied to infer empirical equation linking all the variables used to calculate the maximum scour depth, width, and length under the same conditions applied to this study.

\subsection{The effect of nose angle on maximum local scour depth at different skew angles}

The relative scours depth for each nose angle was plotted against the Froude number, here plotted in Figure 4. The discussion starts with the skew angle at $0^{\circ}$. Data shows that increasing nose angle consistently resulted in decreasing scour depth when the Froude number is increased. The effect of nose angle is significant at low $F_{r}$, where the percentage of reduction was found to be about $43 \%$. Increasing $F_{r}$ however, the percentage of scour depth reduction was decreasing to $24 \%$, comparing $45^{\circ}$ nose angle with the regular pier. A similar trend was observed when the skew angle was increased. Even so, higher skew angle only provides scour reduction about $22.6 \%$ for low $F_{r}$ and the scour depth was appreciably reduced for higher $F_{r}$, with only $18.4 \%$ of reduction was observed.

For the higher skew angle (more than $0^{\circ}$ ) the relative scour depth was much increased as the flow velocity increased. However, data shows that with nose-angle pier, the scour reduction was permitted. Throughout the experimental data, employing a $45^{\circ}$ nose-angle pier resulted in a consistent low scour depth compared to piers with nose angles of $70^{\circ}$ and $60^{\circ}$.

Regression analysis of the data shows that the data obeys a power-law distribution with the relationship $\gamma_{s} \propto F_{r}^{b}$, where $k$ is a constant scaling coefficient. Each value of $k$ was obtained from each data set and plotted against the skew angle $\alpha$, shown here in Figure 5. The scaling parameter was evidently varied for skew angle at $0^{\circ}$,

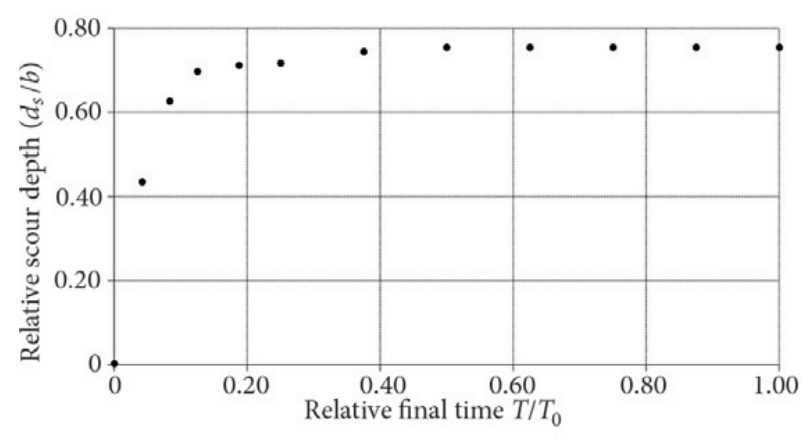

Figure 3. The relative scour depth $d_{s} / b$ against relative final time $T / T_{0}$ at $F_{r}$ equal to 0.44 and nose angle at $90^{\circ}$ 

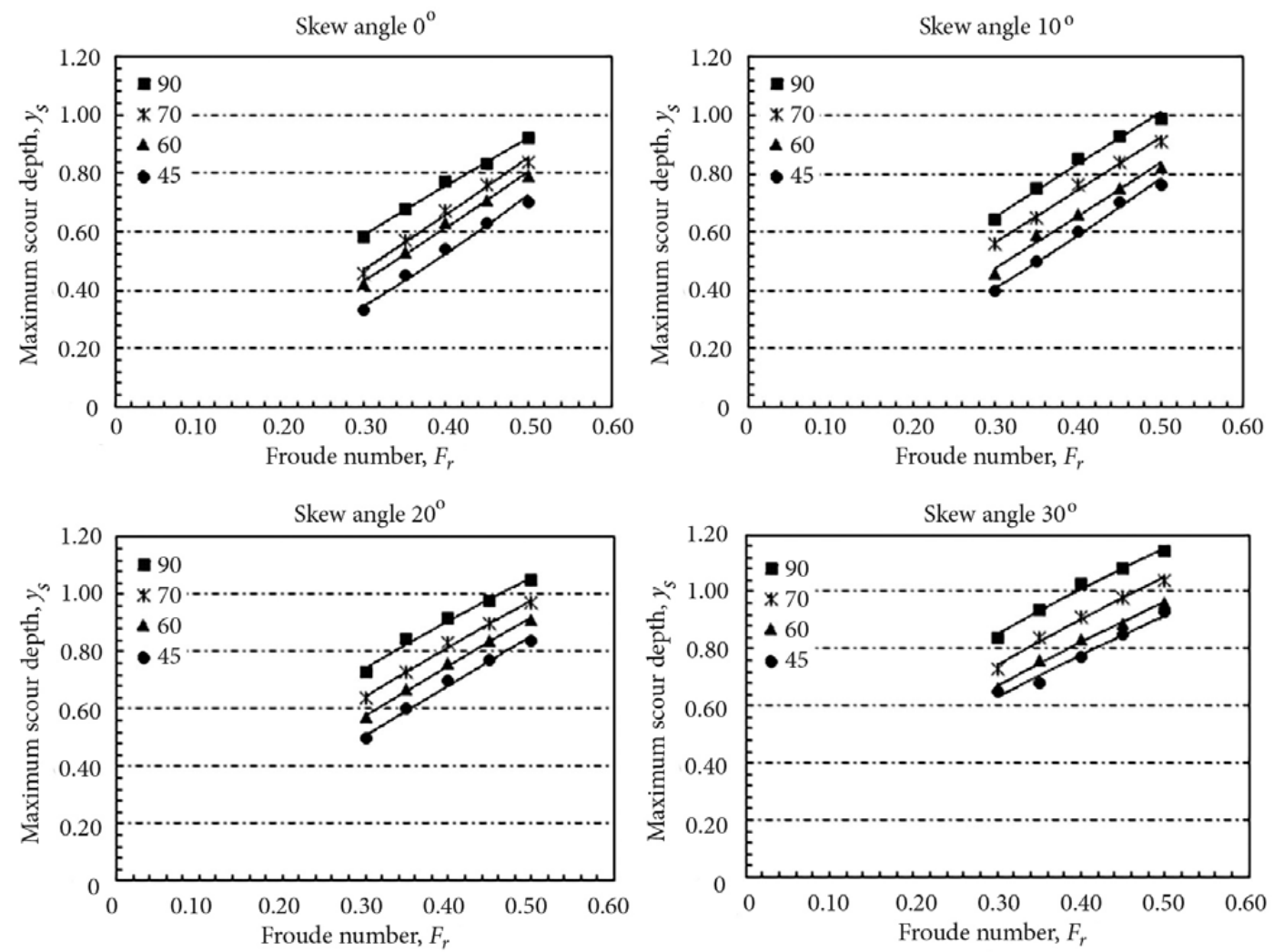

Figure 4. The scour depth against Froude number for bridge piers with different skew angle and for different nose angles

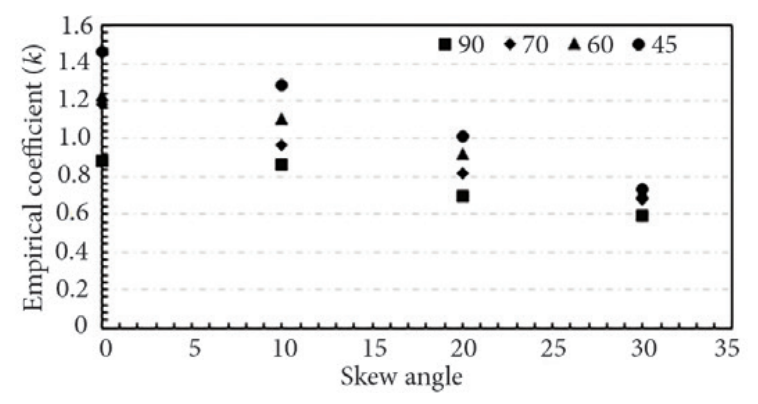

Figure 5. The empirical constantagainst a skew angle for piers with the nose angles

but continuously to have a lesser difference as the skew angle is increased. This indicates that the nose-angle pier does insignificantly reduced the local scour for greater skew angles. Increasing projected pier width gives higher drag forces and promotes flow separation at the downstream. The recirculating turbulent eddies (of which the length scale is approximately $b$ ) and vortex shedding formed entrained more sediment around the pier perimeter.

It is speculated that the reduction in scours depth is due to the reducing intensity of down-flow impinging on the bed due to the sloped nose. As such, the development of scour hole is slow which subsequently retards the formation of horseshoe vortices. With the low intensity of downward flow and horseshoe vortex, which are known to be the dominant scour agent, it can be said to a certain extent that those are the primary mechanism of scouring reduction in this case.

The relationship $y_{s}=\alpha F_{r}^{k}$ was performed on each result to evaluate the scaling coefficient $k$ on a skew angle.
The variation of $\mathrm{k}$ with the skew angle fit in the relationship $k=f(\alpha)$. The empirical constant $k$ however was seen to decrease as the skew angle is increased and reached a relatively similar value between 0.6 and 0.7 . For skew angle at $0^{\circ}$, scouring potential steeply increased for noseangle piers when for higher flow velocity. It is translates that the nose-angle pier, particularly for $45^{\circ}$, only worked well for low $F_{r}$ flow. Higher flow velocity is believed to increase the turbulence and resulted in more entrainment of the bed materials.

However, increasing the skew angle to $30^{\circ}$ showed that the scouring potential is similar for the nose-angle piers. This indicates that the nose-angle piers give less scour reduction than the typical vertical square pier, only for flows with a skew angle of $30^{\circ}$. It is expected that it also works well for flow with a skew angle of $45^{\circ}$, although this is yet to be asserted with confidence.

Pier model with nose angle of $70^{\circ}$ managed to reduce the scour depth up to $21 \%$ but the reduction of scour depth proved to remain unchanged for skew angles $10^{\circ}$ and $30^{\circ}$. Even though the percentage of reduction increased for the nose-angle pier of $60^{\circ}$, similar behaviour was observed when the skew angles were increased from $20^{\circ}$ to $30^{\circ}$.

To assess the physical effect of skew angle on the maximum local scour depth, the profile of depth was plotted against the projected pier Reynolds number $R_{b^{\prime}}$, where $R_{b^{\prime}}=V b^{\prime} / v$ and $b^{\prime}$ denotes the projected width of pier. Figure 2 illustrates the parameter $b^{\prime}$.

Figure 6 shows the dimension less maximum scour depth against the projected pier $R_{b^{\prime}}$, for skew angles $10^{\circ}, 20^{\circ}$ and 
$30^{\circ}$. In general, nose-angle piers were shown to have significant scour reduction, where decreasing nose angle showed a consistent decreasing trend of scour depth. The skew angle 10 is discussed first. The scour depth progressively increased for increased nose angle from $45^{\circ}$ to $90^{\circ}$. A similar trend was observed when the skew angle was increased.

The gradient of scour depth is the steepest for the pier with no nose angle and continued to have less steep gradient when the nose angle is decreased. At high $R_{b^{\prime}}$, the scour depth has a minimal increase when the $45^{\circ}$ noseangle pier was used.

At skew angle $\alpha$ of $20^{\circ}$, there is a significant reduction of scouring for all four pier models compared to when the flow was at skew angle $\alpha$ of 10 . Higher $R_{b^{\prime}}$ gives acceleration to the scour depth, where all models displayed increasing scour depth. Interestingly, for higher $R_{b^{\prime}}$, the nose-angle pier at $45^{\circ}$ has relatively lower scour depth compared to pier model with $90^{\circ}$. Increasing increase the scour depth of $45^{\circ}$ piers; even so, the increment is indefinite where $\frac{d_{s 20}}{b}$ is within the range of 0.26 to 0.38 . Piers with nose angle $60^{\circ}$ has no extra protection to the sediment entrainment, where increasing $R_{b^{\prime}}$ were insignificant and the scour depth $\frac{d_{s 20}}{b}$ was around 0.40 . This finding indicates that the nose-angle piers works well in keeping the scour depth at its minimum level even at high $R_{b^{\prime}}$.

The maximum scour depth was seen to appreciably decreased when the skew angle is at 30, notably for noseangle piers of $90^{\circ}$ and $70^{\circ}$. The lower nose-angle piers of $60^{\circ}$ and $45^{\circ}$ too exhibited reduction scour depth, where $\frac{d_{s 30}}{b}$ is around 0.20 , independent of $R_{b^{\prime}}$. This analysis indicates that for skewed flow at $30^{\circ}$, the increase in $R_{b^{\prime}}$ is insignificant, for piers with the angle less than $70^{\circ}$.

For pier model, $\theta$ is equal to $90^{\circ}$, a steep gradient as pier $R_{b^{\prime}}$, increased was consistently observed, independent of the angle of attack. A similar profile was also found for the nose-angle pier of $70^{\circ}$. Interestingly, however, gentler nose-angle pier (i.e., $\alpha$ is equal to $60^{\circ}$ and $45^{\circ}$ ) exhibited different profile as the skew angle increased. When the flow is made at angle $10^{\circ}$, piers with nose angle of $45^{\circ}$ and $60^{\circ}$ displayed a gradual increase of maximum scour depth as the pier $R_{b^{\prime}}$, increased. Increasing skew angle to a is equal to $20^{\circ}, \frac{d_{s}}{b}$ was seen to increased become steeper for data $a$ is equal to $30^{\circ}$ sharply. This finding indicates that that the direction of incoming flow to the pier is significant when $\alpha$ is more than $10^{\circ}$.

On the other hand, by decreasing the nose angle $\theta$ from $90^{\circ}, 70^{\circ}, 60^{\circ}$ to $45^{\circ}$ at a constant value of $R_{b^{\prime}}$ the relative scour depth $\frac{d_{s}}{b}$ goes down for each Figures $6 \mathrm{a}, 8 \mathrm{~b}$ and $8 \mathrm{c}$.

\subsection{The skew angle effect on the local scour characteristic}

In this section, the effect of skew angle on the local scour at the upstream nose is studied for each pier model separately.

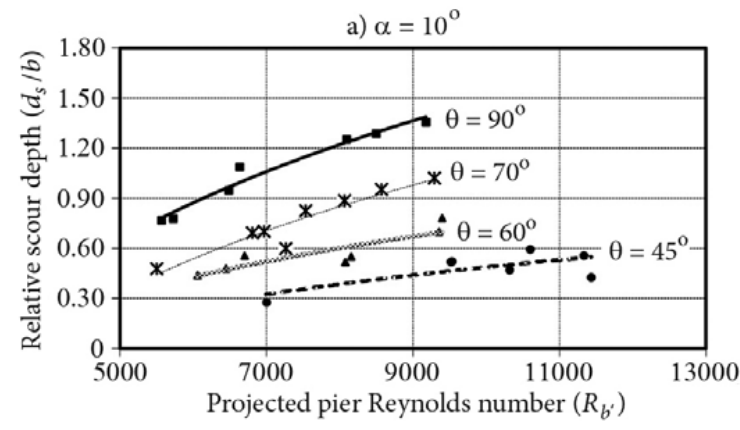

b) $\alpha=20^{\circ}$

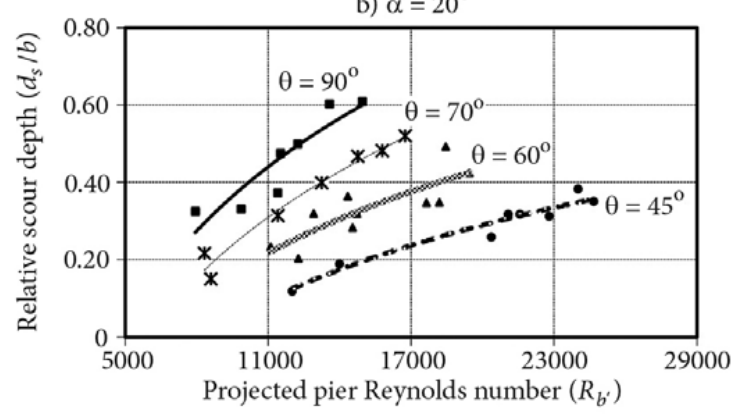

c) $\alpha=30^{\circ}$

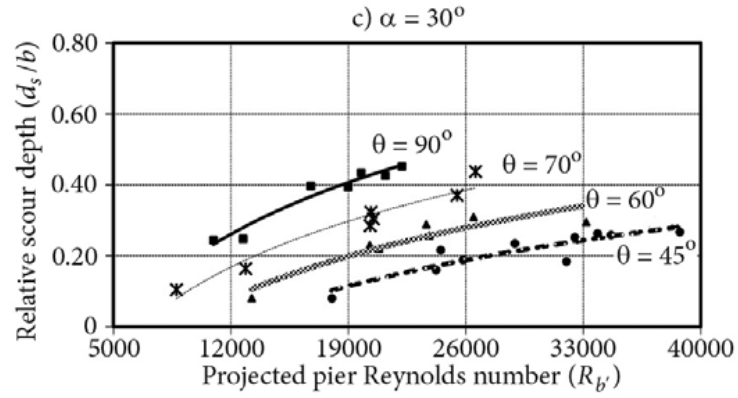

Figure 6. The relationship between relative scour depth and the projected Reynolds number of the nose-angle pier with the varying skew angle

The analysis includes the relative depth, width, both right and left transversal lengths scour developed. Recall Figure 2 for the representation of a typical topography profile around pier models for the set of experiments with the skew angle. Note that $l_{r}$ has a lower value than $l_{l}$ due to deposition of sediment behind the pier. Entrained sediment from the upstream is settled here as the flow velocity decreases.

\subsubsection{For nose angle $\theta=90^{\circ}$}

Figure $7 \mathrm{a}$ shows the relationship among relative scour depth $\frac{d_{s}}{b}$ at the upstream nose of the pier against the Froude number $F_{r}$ for different a (i.e., $0^{\circ}, 10^{\circ}, 20^{\circ}$ and $30^{\circ}$ ). Data shows that in general, increasing $F_{r}$ and skew angles give a deeper scour depth. The scour depth monotonously increased as $F_{r}$ increased. High skew angles increased the contraction ratio in channel width and as a result increasing the scour depth. Percentage in the increase was $7 \%$ at $\alpha=10^{\circ}$, $15 \%$ at $\alpha=20^{\circ}$ and $27 \%$ at $\alpha=30^{\circ}$ compared to $\alpha=0^{\circ}$.

The variation among $\frac{W_{s}}{b}$ with $F_{r}$ for different skew angles of $\left(0^{\circ}, 10^{\circ}, 20^{\circ}\right.$ and $\left.30^{\circ}\right)$ are shown in Figure $7 \mathrm{~b}$. 
It is clear that the width of scouring $\frac{W_{s}}{b}$ increases with increasing of $F_{r}$. Furthermore, the increases in skew angles a contribute to the increase of scouring width.

Figure $7 \mathrm{c}$ shows the scour characteristics of the horizontal scour distance at both left $\frac{l_{l}}{b}$ and right $\frac{l_{r}}{b}$ sides of the pier for skew angles $a$ of $0^{\circ}, 10^{\circ}, 20^{\circ}$ and $30^{\circ}$. Recall the representation of $\frac{l_{l}}{b}$ and $\frac{l_{r}}{b}$ is depicted in Figure 2.

The $\frac{l_{l}}{b}$ progressively increased as the Froude number and skew angle were increased. The maximum left longitudinal scour was obtained at eight times more than the diameter for the range of $F_{r}$ used in this study. At low $F_{r}$, (less than 0.40) $\frac{l_{l}}{b}$ is within the range of $2.0<\frac{l_{l}}{b}<4.0$, and much appreciably increased for higher $F_{r}$. The flow angles clearly have an effect of the development of right longitudinal scour, whereby data shows a much lesser scour compared to the. For low $F_{r}$, the developed $\frac{l_{r}}{b}$ is within the range 2 and only have a slight increment to $\frac{l_{r}}{b}$ around 4.0 for higher $F_{r}$.

Furthermore, the relationship between the relative scour hole length at left side $\frac{l_{r}}{b}$, and Froude number $F_{r}$ is displayed in Figure $7 \mathrm{~d}$. Initially noted that all the curves increased rapidly with increase $F_{r}$ from 0.20 to 0.45 for all skew angles, i.e., $10^{\circ}, 20^{\circ}$ and $30^{\circ}$. Even so, the rate of increase was slightly decreased after $F_{r}$ equal to 0.45 . Although with the increased flow velocity, the development of the upstream length of scour hole at the right side $l_{r}$ was hindered due to the fast emergence of deposition area in the right side of the pier.

It was noted that with an increase in $F_{r}$ for the same $\alpha$, the scour hole length at left side increased faster than the

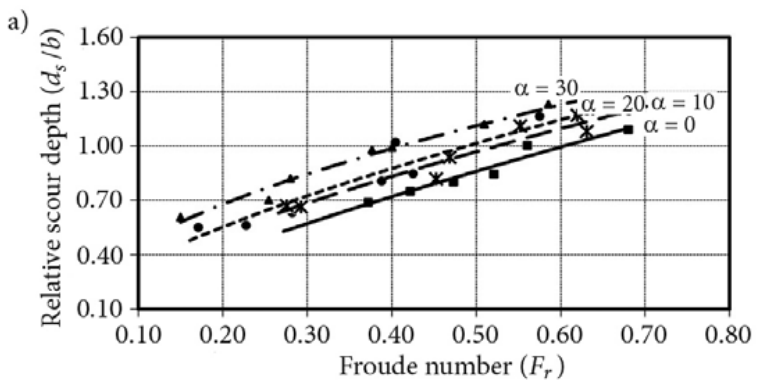

c)

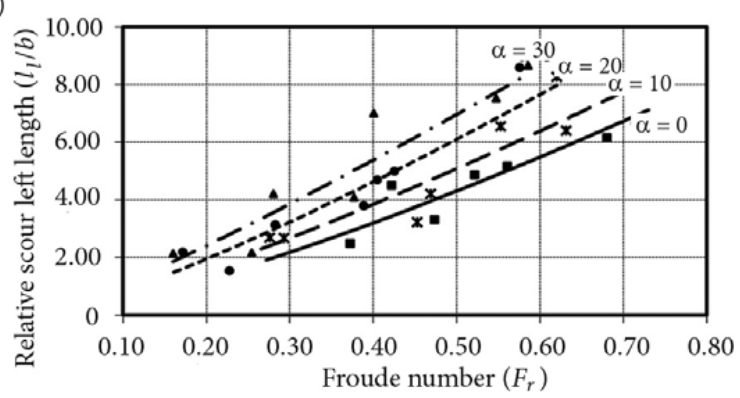

scour hole length at right side for all models, comparing the lengths of scour holes at left and right side $\left(l_{l}\right.$ and $\left.l_{r}\right)$, discussed in this study.

\subsubsection{For nose angle $\theta=70^{\circ}$}

The effect of Froude number $F_{r}$ on the relative scour depth $\frac{d_{s}}{b}$ at different skew angle $a$ for the pier with nose angle equal to $70^{\circ}$ is shown in Figure 8. In general, data shows that increasing $F_{r}$ and skew angle resulted in higher scour depths and widths. Figure $8 \mathrm{a}$ shows that there is a sudden increase in scour depth when the skew angle is increased. For example, at Fr equals to 0.20 , the scour depth jumped from $\frac{d_{s}}{b}$ equal to 0.15 to $\frac{d_{s}}{b}$ equal to 0.40 for skew angle at $10^{\circ}$. Also, this profile is continued throughout the range of $F_{r}$ studied here. However, increase in scour depth is rather insignificant when the skew angle is more than $10^{\circ}$. The added hindrance from the nose angle enhanced the drag and turbulent intensity, which promoted more of the sediment entrainment from the bed.

The scour longitudinal lengths are further discussed. Data shows that increasing $F_{r}$ and skew angle resulted in longer scour longitudinal lengths for both sides. The $l_{r}$ has lower scour values than $l_{l}$ due to the pier orientation, and is consistent throughout the increase in $F_{r}$ and skew angle.

The effect of skew angle here differs from pier $90^{\circ}$, where higher skew angle exhibits a rather more uniform and consistency increment in the scour depths and widths. The nose-angle pier shape proved to affect the scour longitudinal lengths where increasing $F_{r}$ gives a significant increase in $l_{l}$ and $l_{r}$. Note that although the largest relative $\frac{l_{l}}{b}$ here is about 8 (as obtained for experiments with $90^{\circ}$ pier), the $\frac{l_{l}}{b}=8$ was obtained at lower $F r$, i.e. 0.45 (compared to $F_{r}$ equal to 0.6 for pier $90^{\circ}$ ), shown in Fig-

b)

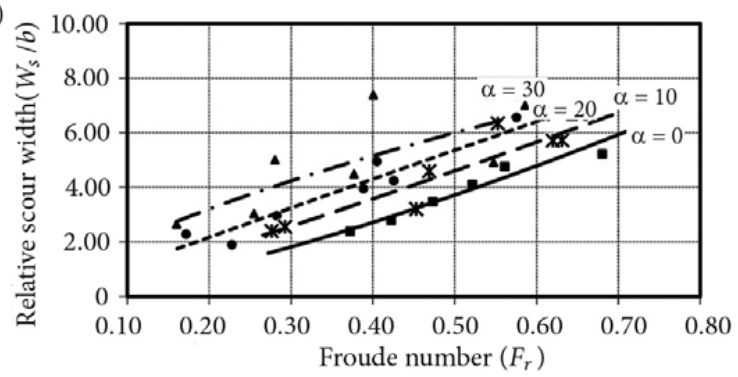

d)

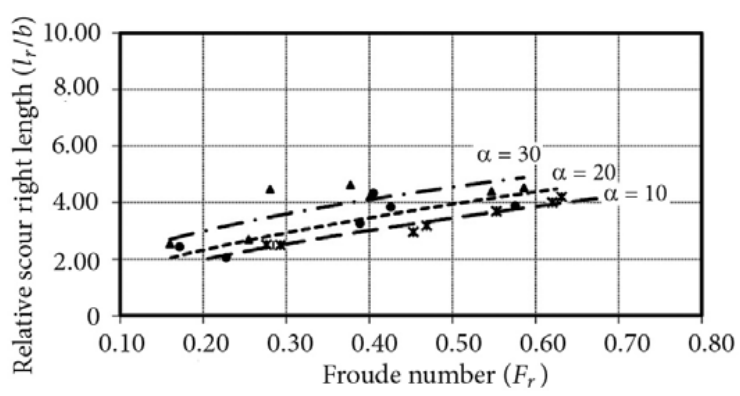

Figure 7. Froude number against relative scour depth, width, left side length and right side length with the varying skew angles 
ure $8 \mathrm{~d}$. The flow velocity affects the right scour longitudinal length where it was shown to have a considerable increase when $F_{r}$ more than 0.40 . For higher $F_{r}$, the $l_{r}$ increased tremendously.

\subsubsection{For nose angle $\theta=60^{\circ}$}

The results for the nose-angle pier at $60^{\circ}$ also depicted similar results with the previous discussed nose-angle piers where increasing $F_{r}$ and skew angle gave a higher scour depths and widths. Figure 9 displays the changes of scour depth with varying Froude number $F_{r}$ for different skew angles (i.e., $0^{\circ}, 10^{\circ}, 20^{\circ}$ to $30^{\circ}$ ) for nose angle at $60^{\circ}$. It is first noted that the relationship between $\frac{d_{s}}{b}$ and $F_{r}$ has taken the same trend for all value of $\alpha$. The increase in scouring width, however, displayed a different trend.
At higher $F_{r}$ more than 0.40 , the scour width is much increased for all skew angle discussed here, shown in Figure 9.

The relationship between the transverse lengths of scour holes at left and right side $\left(l_{l}\right.$ and $\left.l_{r}\right)$ and Froude number $F_{r}$ is presented in Figures $9 \mathrm{c}$ and $9 \mathrm{~d}$. It is clear that increase in Froude number resulted in the increase of the length of scour hole. However, the lengths of scouring at the left side of the pier were exponentially increased, and a monotonous increase was observed in the right transverse length due to deposition region at the right side of the pier.

\subsubsection{For nose angle $\theta=45^{\circ}$}

The scour profile for the gentlest nose angle is further discussed. Figure 10 shows the scour depth and width profiles for various $F_{r}$ and skew angles. The effect of $F_{r}$ is obvious
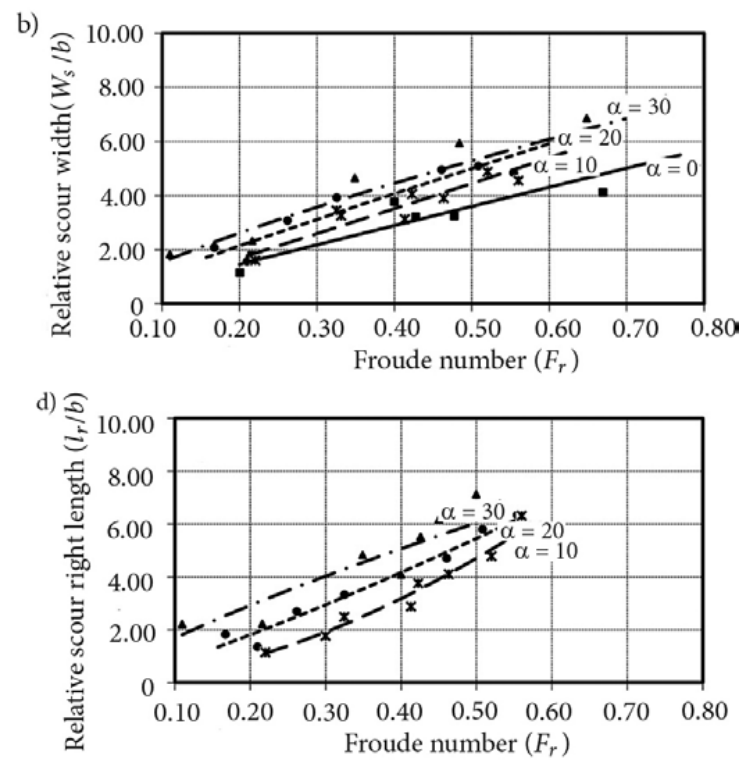

Figure 8. Froude number against relative scour depth, width, left side length and right side length with the varying skew angle

a)

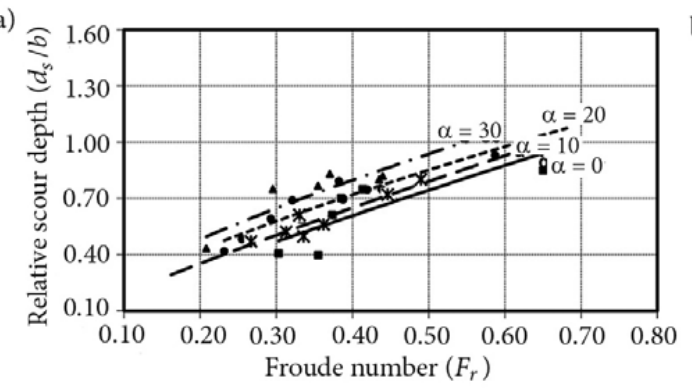

c)

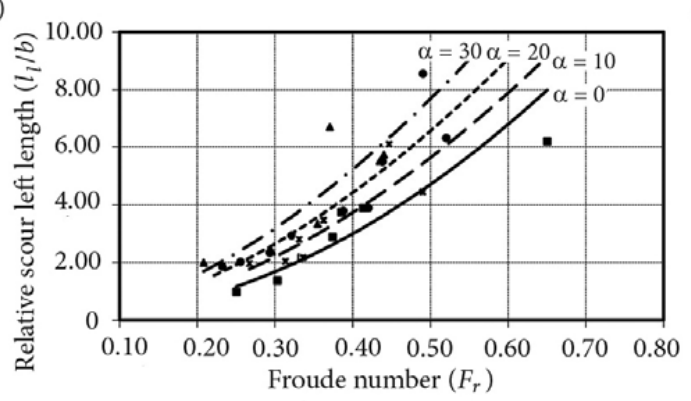

b)

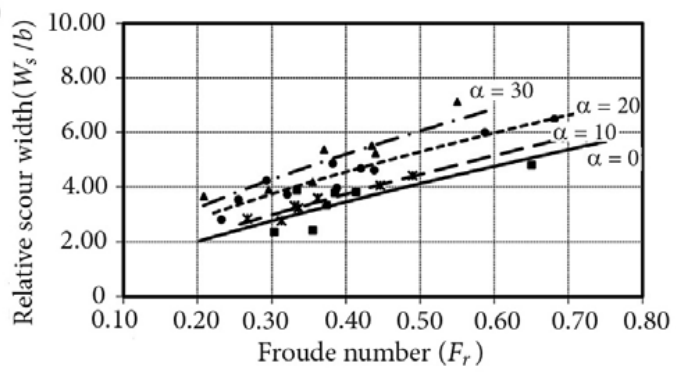

d)

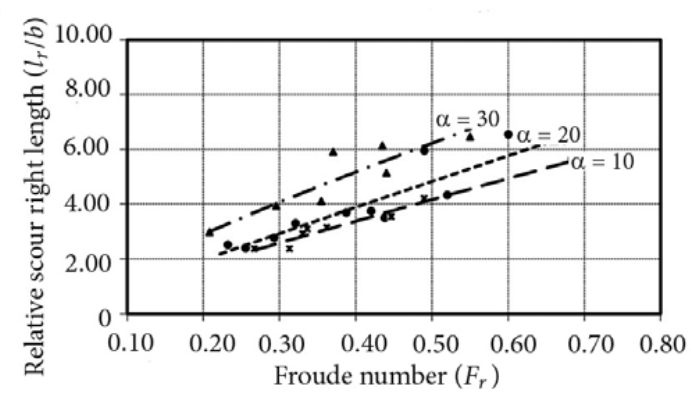

Figure 9. Froude number against relative scour depth, width, left side length and right side length with the varying skew angle 


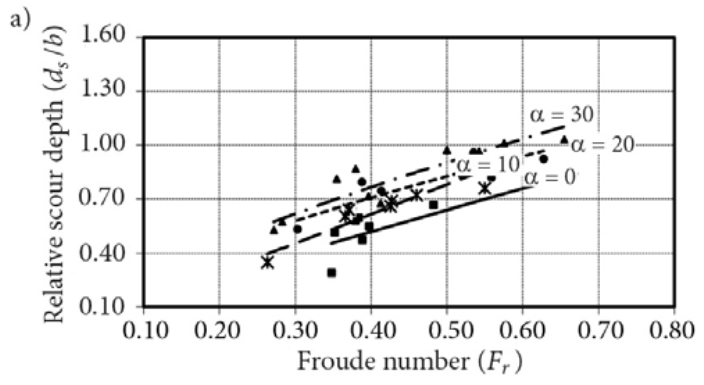

c)

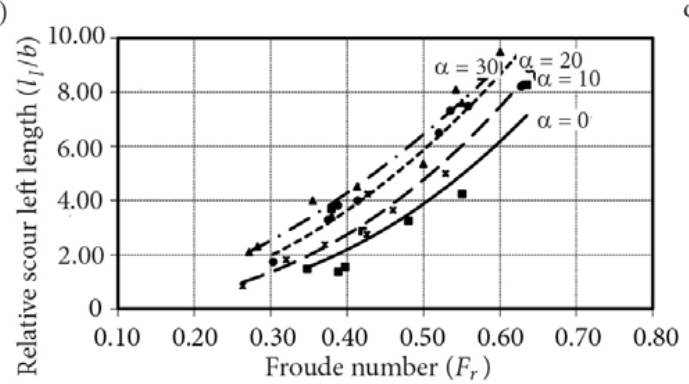

b)

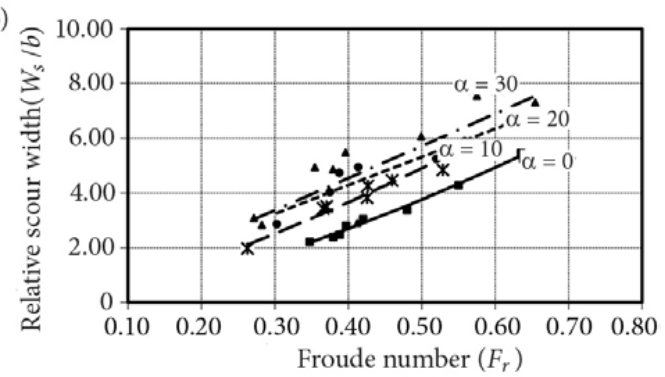

d)

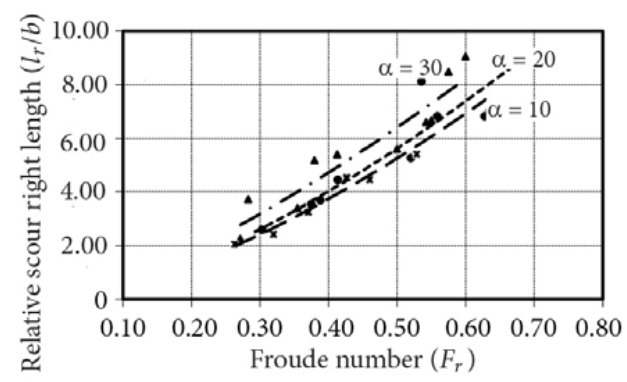

Figure 10. Froude number against relative scour depth, width, left side length and right side length with the varying skew angle

as the flow is moving to critical flow (from subcritical), the scour depth and width were found to be increased. The scour depth and width drew deeper and longer, respectively when the skew angle is increased. Scouring process was accelerated due to increasing projected width, as the skew angle is increased. However, the relative scours depth increased in a lower increment compared to nose angle piers of $\theta=70^{\circ}$ and $\theta=60^{\circ}$.

The relationship between lengths of scour holes at left and right side $\left(l_{l}\right.$ and $\left.l_{r}\right)$ and Froude number $F_{r}$ is presented in Figures 10c and 10d, respectively. It is clear that increasing in Froude number resulted in increasing the length of scour hole. However, there was a different visible trend observed for $l_{l}$ where the scour length increased exponentially as Froude number increased. This finding indicates the depositional area behind the pier is depleting. It was evident that $l_{r}$ for $\theta=45^{\circ}$ here is much deeper compared to the value obtained for experiments with $\theta=60^{\circ}$ piers due to the restriction of flow as the projected width is increased.

At a higher skew angle, i.e. $20^{\circ}$ and $30^{\circ}$, the nose angled piers of $60^{\circ}$ and $45^{\circ}$ keep the scour minimum even at high $F_{r}$. The nose angled piers were able to reduce the upstream maximum scour depth and width but increased transversal lengths for higher skew angles. Skewed piers resulted in highly asymmetrical scour pattern with the maximum scour localized on the side towards which direction the pier is skewed to.

\subsection{Empirical relations}

Empirical equations were derived using the Multiple Linear Regression (M.L.R) method for estimating the relative scour depth $\frac{d_{s}}{b}$, the relative transversal scour lengths $\frac{l_{l}}{b}$ and $\frac{l_{r}}{b}$, and the relative scour width $\frac{W_{s}}{b}$ as a function of $R_{n s}, F_{r}^{2}, \frac{h_{u}}{b}, \frac{b^{\prime}}{b}, \frac{\theta}{90}$ and $\left(\frac{\alpha}{90}\right)^{0.1}$. Recall that there were 282 runs conducted. For the MLR analysis, randomly selected data from 120 runs were used where the rest of the data was used for validation. The Eqs (4-7) obtained for $\frac{d_{s}}{b} ; \frac{l_{l}}{b}$, and $\frac{W_{s}}{b}$ are presented as:

$$
\begin{aligned}
\frac{d_{s}}{b}= & -0.106+0.409 F_{r}^{2}+0.0006 R_{n s}-0.283 \frac{h_{u}}{b}+ \\
& +0.0066 \frac{b^{\prime}}{b}+0.52 \frac{\theta}{90}+0.049\left(\frac{\alpha}{90}\right)^{0.1},
\end{aligned}
$$

$$
\begin{aligned}
\frac{l_{l}}{b}= & 0.726+15.620 F_{r}^{2}-0.002 R_{n s}-2.127 \frac{h_{u}}{b}+ \\
& +0.456 \frac{b^{\prime}}{b}+1.190 \frac{\theta}{90}+0.982\left(\frac{\alpha}{90}\right)^{0.1},
\end{aligned}
$$

$$
\begin{aligned}
\frac{l_{r}}{b}= & 0.502+10.360 F_{r}^{2}+0.013 R_{n s}-0.686 \frac{h_{u}}{b}+ \\
& +0.703 \frac{b^{\prime}}{b}-0.027 \frac{\theta}{90}+0.037\left(\frac{\alpha}{90}\right)^{0.1},
\end{aligned}
$$

$$
\begin{aligned}
\frac{W_{s}}{b} & =0.049+3.380 F_{r}^{2}+0.031 R_{n s}-1.184 \frac{h_{u}}{b}+ \\
& +0.481 \frac{b^{\prime}}{b}+0.845 \frac{\theta}{90}+0.648\left(\frac{\alpha}{90}\right)^{0.1},
\end{aligned}
$$

The data were plotted to assess the performance between the measured and the calculated values from the empirical equations, as shown in Figures 11a-11d. Figure 11a shows that in general, the calculated parameters agreed with the measured values particularly for relative scour depth $\frac{d_{s}}{b}$. The Standard Error of Estimation (SEE) was obtained at $0.08,1.20,1.40$, and 0.70 for $\frac{d_{s}}{b}, \frac{l_{l}}{b}, \frac{l_{r}}{b}$ 
a)

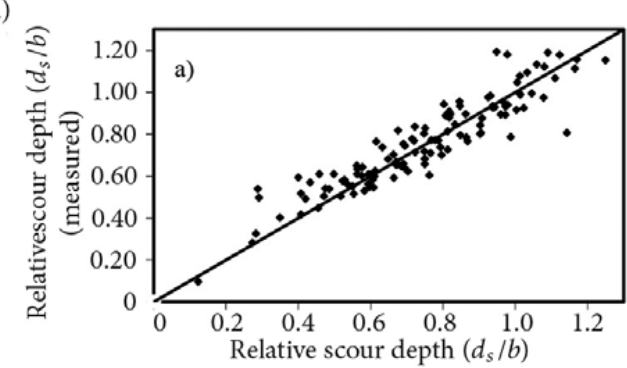

(calculated)

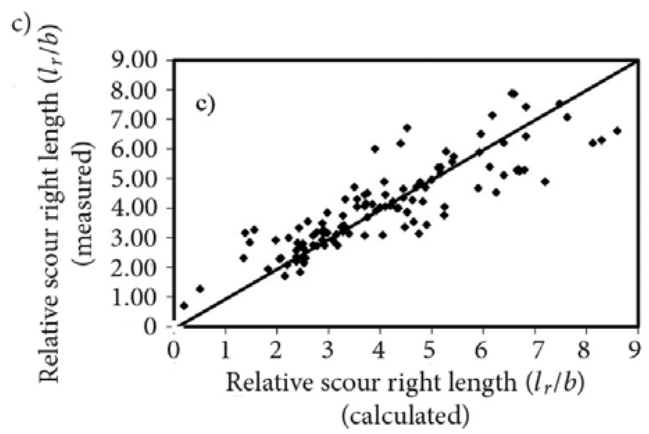

b)

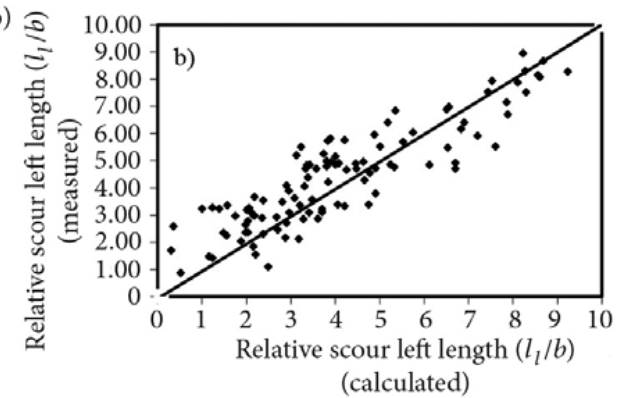

d)

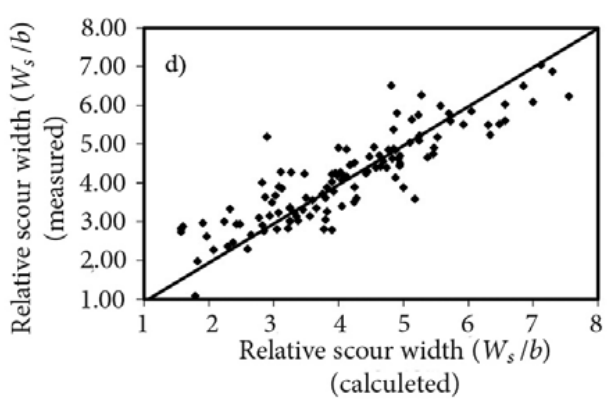

Figure 11. The predicted vs calculated scour hole characteristics

and $\frac{W_{s}}{b}$. The transverse lengths for both left and right sides have the highest SEE either for low and high values.

A regression analysis of the results to establish the fitting of the data was also conducted. The coefficient $R^{2}$ was obtained at acceptable values, i.e. $85 \%, 78 \%, 73 \%$, and $76 \%$ for $\frac{d_{s}}{b}, \frac{l_{l}}{b}, \frac{l_{r}}{b}$ and $\frac{W_{s}}{b}$. As seen in Figure 11a, the $85 \%$ variance response indicates that the data fits the model very well. Most of the points are either on the line of agreement or very close to it. The data was scattering away from the line of agreement for $\frac{l_{l}}{b}, \frac{l_{r}}{b}$ and $\frac{W_{s}}{b}$ equations, with $\frac{l_{r}}{b}$, has the lowest coefficient.

\section{Conclusions}

1. The percentage of reduction was found up to $43 \%$, obtained from the protection given by the $45^{\circ}$ nose-angle pier. The different skew angle, i.e. angle of flow attack was also examined, and the maximum scour depth, transversal lengths, and width of scouring were measured for each model.

2. This approach proved to be effective in reducing the scour depth where the decreasing nose angle gives the lowest maximum scour depth. The flow angle or skew angle (as has been discussed throughout this study) is an important variable where the increasing skew angle provides deeper scour for low Froude number flow.

3. At high $F_{r}$ with the skewed flow of $10^{\circ}$ and $20^{\circ}$ however, the nose angle play an insignificant factor and not necessarily reduces the scour.

4. Increasing skew angle increases the projected pier width, which resulted in the contraction of the flume.
As such, the flow velocity is enhanced, whereby the increasing turbulence intensity entrained sediment away from the bed.

5. Therefore, $45^{\circ}$ nose-anglepier with its placement perpendicular to the flow (i.e., skew angle $0^{\circ}$ ) is proposed as the best nose-angle pier design as local scour countermeasure.

\section{References}

Akib, S., Liana Mamat, N., Basser, H., \& Jahangirzadeh, A. (2014). Reducing local scouring at bridge piles using collars and geobags. The Scientific World Journal, 2014.

https://doi.org/10.1155/2014/128635

Beg, M., \& Beg, S. (2013). Scour reduction around bridge piers: a review. International Journal of Engineering Inventions, 2(7), $7-15$.

Chiew, Y. M., \& Melville, B. M. (1987). Local scour around bridge piers. Journal of Hydraulic Research, 25(1), 15-26. https://doi.org/10.1080/00221688709499285

Chiew, Y. M. (1992). Scour protection at bridge piers. Journal of Hydraulic Engineering, 118(9), 1260-1269. https://doi.org/10.1061/(ASCE)0733-9429(1992)118:9(1260)

Ferraro, D., Tafarojnoruz, A., Gaudio, R., \& Cardoso, A. H. (2013). Effects of pile cap thickness on the maximum scour depth at a complex pier. Journal of Hydraulic Engineering, 139(5), 482491. https://doi.org/10.1061/(ASCE)HY.1943-7900.0000704

Grimaldi, C., Gaudio, R., Cardoso, A. H., \& Calomino, F. (2006). Local scouring at bridge piers and abutments: time evolution and equilibrium. Proceedings of $3^{\text {rd }}$ International Conference on Fluvial Hydraulics (pp. 1657-1664).

Gupta, A. K., \& Gangadharaiah, T. (1992). Local scour reduction by a delta wing-like passive device. Proceedings of the 8th Congress of Asia \& Pacific Regional Division. Vol. 2. Pune, India.

Habib, I. A. M. (2007). Study the local scour around bridge piers (sloped noses and skew angles) (Master Thesis). Al-Marigb University, Al-Khoms, Libya. 
Kumar, V., Raju, K. G. R., \& Vittal, N. (1999). Reduction of local scour around bridge piers using slots and collars. Journal of hydraulic engineering, 125(12), 1302-1305.

https://doi.org/10.1061/(ASCE)0733-9429(1999)125:12(1302)

Lagasse, P. F., Clopper, P. E., \& Zevenbergen, L. W. (2007). Countermeasures to protect bridge piers from scour. NCHRP Report 593, Transportation Research Board, National Academies of Science, Washington, D.C.

Lin, Y. B., Chen, J. C., Chang, K. C., Chern, J. C., \& Lai, J. S. (2004). Real-time monitoring of local scour by using fiber Bragg grating sensors. Smart materials and structures, 14(4), 664. https://doi.org/10.1088/0964-1726/14/4/025

National Transportation Safety Board. (1990). Highway accident report. Retrieved from http://www.ntsb.gov/investigations/ summary/HAR900/html

Ross, H., Sicking, D, Zimmer, R., and Michie, J. (1993). Recommended procedures for the safety performance evaluation of highway features. National Cooperative Highway Research Program, Report 350. Transportation Research Board, National Academy Press.

Richardson, E. V., \& Davis, S. R. (2001). Evaluating scour at bridges (4th ed.). Federal Highway Administration Hydraulic Engineering Circular No.18, FHWA NHI 01-001.

Odgaard, A. J., \& Wang, Y. (1987). Scour prevention at bridge piers. In Hydraulic Engineering (pp. 523-527). ASCE.

Yoon, T. H., \& Kim, D. H. (2001). Bridge pier scour protection by sack gabions. In Bridging the Gap: Meeting the World's Water and Environmental Resources Challenges (pp. 1-8). American Society of Civil Engineers (ASCE). https://doi.org/10.1061/40569(2001)256

Zarrati, A. R., Nazariha, M., \& Mashahir, M. B. (2006). Reduction of local scour in the vicinity of bridge pier groups using collars and riprap. Journal of Hydraulic Engineering, 132(2), 154-162. https://doi.org/10.1061/(ASCE)0733-9429(2006)132:2(154) 